\title{
PENDIDIKAN KONSERVASI UNTUK SISWA SD TENTANG KEANEKARAGAMAN BUAH LOKAL DAN MANFAATNYA
}

\author{
Fabiola Baby Saroinsong1, dan Wawan Nurmawan2 \\ 1 Fakultas Pertanian, Universitas Sam Ratulangi \\ Email: fabiolasaroinsong@unsrat.ac.id \\ 2 Fakultas Pertanian, Universitas Sam Ratulangi \\ Email: wawan2828@yahoo.com
}

\begin{abstract}
High flora biodiversity provides many functions, both ecological, economic, social, aesthetic and security. People's preference for a variety of local fruits can increase their motivation to plant and maintain various fruit-producing plants, and manage biodiversity in general. The problem agreed by the Team and the two partners was, the low knowledge of students about the diversity of local fruits and their benefits, on the other hand the students were accustomed to consuming imported fruit. In the long run, it can have implications for the lack of preference for local fruits, as well as the low appreciation for the existence of local fruit-producing plants. The solution offered is to introduce local fruits, local fruit-producing trees, their benefits for health and for the environment. Environmental education is needed to prepare the community with knowledge and skills; preparing them to understand environmental problems, motivating to act, and equipping with skills and abilities to solve or prevent certain environmental problems. It is expected that the student group of INPRES elementary school and St. Catholic elementary school Agustinus Warembungan (main targets) and the teachers and students involved (additional targets) gained knowledge about the diversity of local fruits and their benefits and were able to plant and maintain local fruit-producing trees in the school and residential areas. PKM was held in Warembungan Village, Pineleng District, Minahasa Regency, North Sulawesi Province for six (6) months. The program is carried out in the following activities. 1) Preparation of the program with partners. 2) Preparation of teaching modules and teaching aids introducing discussion, as well as preparation of demonstration tools and materials and student practice. 3) Implementation of extension activities in the form of discussion and demonstration with active learner involvement (direct experience). 4) Compilation of reports and writing articles for scientific publication.
\end{abstract}

Keywords: biodiversity management, environmental education, flora diversity, local fruit 


\section{PENDAHULUAN}

Penurunan biodiversitas flora merupakan salah satu dari berbagai masalah lingkungan yang serting ditemui. Padahal biodiversitas flora yang tinggi menyediakan banyak fungsi, baik ekologi, ekonomi, estetika maupun ameniti. Kecintaan masyarakat terhadap aneka ragam buah lokal dapat meningkatkan motivasi mereka untuk menanam dan memelihara tanaman-tanaman penghasil buah secara khusus, dan mengelola biodiversitas secara umum (Saroinsong dan Kalangi, 2016; Saroinsong dan Kalangi, 2018). Dalam skala yang besar, penurunan biodiversitas flora menyebabkan terganggunya perekonomian daerah dan pengelolaan lingkungan berkelanjutan (Kodoatie, dan Sjarief, 2008; Bennett, Peterson, and Gordon, 2009; de Groot et al., 2009; Reyers, 2009; Asdak, 2010; Bryan et al., 2010; Oktaviana, 2012; Asdak, 2014; Ahmadi, Sadeghi and Eskandarinezhad, 2016; Oran, 2016).

Kurangnya pendidikan lingkungan tentang pemanfaatan sumberdaya alam dengan tetap mempertahankan keberlanjutannya, menjadi akar permasalahan dari banyaknya masalah penurunan kualitas lingkungan (Monroe, Andrews, and Biedienweg, 2007; Hasbullah, 2008; Kodoatie dan Sjarief, 2008; Wascher dan Haines-Young, 2009; Kardan, 2015). Bila pendidikan lingkungan masyarakat tidak memadai, maka sikap (mind set), perilaku (behaviour), dan peran aktif (participation) masyarakat untuk menjaga kelestarian lingkungan pun rendah (Monroe, Andrews, and Biedienweg, 2007; Neolaka, 2008; Soerjani, 2009; Sasaoka and Laumonier, 2012; Setyowati, Sunarko, dan Sedyawaati, 2014). Padahal, membentuk, merubah atau mempengaruhi pola pikir dan perilaku seseorang adalah hal yang tidak mudah. Karena itu pendidikan lingkungan perlu dilakukan sejak dini menjadi hal yang sangat penting sehingga pemahaman dan apresiasi terhadap lingkungan, serta tindakan konservasi menjadi bagian sikap dan kebiasan hidup masyarakat, secara individu ataupun bersama (Neolaka, 2008; Pamuti, Polii, dan Djarkasi, 2014; Hacieminoglu, 2015; Muslicha, 2015; Rombang, Thomas, Saroinsong, 2017; Saroinsong, Nurmawan, Sendouw, 2018).

Kegiatan PKM ini dilaksanakan dengan maksud meningkatkan pendidikan lingkungan kepada masyarakat sejak dini. Segmen masyarakat yang dipandang strategis sebagai sasaran pendidikan lingkungan hidup adalah anak pada usia dini. Pada masa usia dini perlu dikenalkan dan ditanamkan nilai-nilai mencintai dan mengapresiasi lingkungan hidup, sehingga dalam diri mereka terbentuk sikap peduli terhadap lingkungan hidup. Mereka diharapkan menjadi generasi yang sadar lingkungan. (Setyowati et al., 2014; Pamuti, Polii, dan Djarkasi, 2014; Hacieminoglu, E. 2015; Muslicha, 2015). PKM ini menyasar anak-anak SD INPRES dan SD Katolik St. Agustinus Warembungan yang terletak di Kecamatan Pineleng Kabupaten Minahasa (Gambar 1).

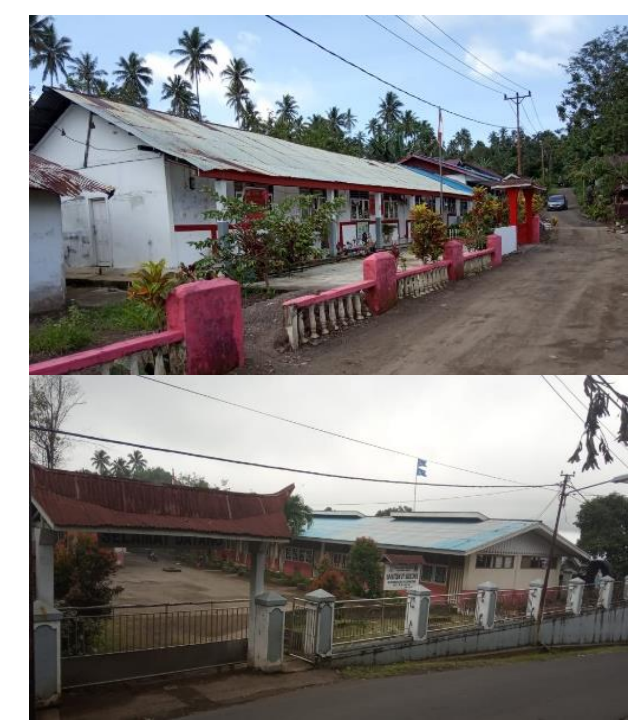

Gambar 1. Foto Survey Awal di SD INPRES

(kiri) dan SD Katolik St. Agustinus (kanan) Warembungan

Selain siswa-siswa kedua SD tersebut, sasaran tambahan adalah guru-guru dan mahasiswa yang dilibatkan. Guru memiliki profesi strategis dalam pendidikan anak, bahkan dikatakan sebagai agent of change. Anak-anak melihat perilaku guru sebagai teladan atau contoh bagi mereka (Hasbullah, 2008; Santosa, 2004). Dengan melibatkan guru-guru SD INPRES dan SD Katolik St. Agustinus Warembungan sejak awal pelaksanaan sampai selesai, diharapkan tim pelaksana bisa juga mentransfer iptek konservasi terhadap mereka. Dengan demikian, setelah pelaksanaan pengabdian selesai, guru-guru dapat menjadi evaluator dan pendamping, bahkan teladan bagi siswa-siswa dalam mengaplikasikan tindakan-tindakan praktis konservasi. Sedangkan mahasiswa yang akan dilibatkan adalah mahasiswa yang sedang mengontrak mata kuliah Ekologi Umum dan Pendidikan Konservasi. Melibatkan mereka untuk turut mendampingi dan mengajarkan anak-anak sebenarnya merupakan metode efektif sebagai penguatan mengenai keanekaragaman 
buah lokal secara khusus dan pengelolaan biodiversitas secara umum (Hasbullah, 2008; Neolaka, 2008; Setyowati et al., 2014; Tugurian and Carrier, 2017).

Persoalan prioritas yang disepakati oleh Tim Pengusul dan mitra untuk diselesaikan selama pelaksanaan program PKM adalah rendahnya pengenalan siswa tentang keanekaragaman buah lokal dan manfaatnya, di lain pihak makin terbiasanya siswa mengkonsumsi buah impor. Dalam jangka panjang, dapat berimplikasi pada kurangnya kecintaan pada buah-buah lokal, serta rendahnya apresiasi pada keberadaan tumbuhtumbuhan penghasil buah lokal. Dengan demikian kegiatan PKM ini menjadi satu langkah yang berkontribusi pada manajemen penanggulangan kebencanaan dan lingkungan.

Solusi yang ditawarkan adalah dengan memperkenalkan buah-buah lokal, pohon-pohon penghasil buah lokal, manfaatnya bagi kesehatan maupun bagi lingkungan. Pendidikan lingkungan diperlukan untuk menyiapkan masyarakat dengan pengetahuan dan keterampilan; menyiapkan mereka untuk mengerti permasalahan lingkungan, memotivasi untuk bertindak, dan melengkapi dengan keterampilan dan kemampuan untuk memecahkan atau mencegah masalah lingkungan tertentu. Diharapkan kelompok siswa kelompok siswa SD INPRES dan SD Katolik St. Agustinus Warembungan (sasaran utama) serta guru dan mahasiswa yang dilibatkan (sasaran tambahan) bertambah pengetahuannya mengenai keanekaragaman buah lokal dan manfaatnya serta dapat menanam dan memelihara pohon-pohon penghasil buah lokal di lingkungan sekolah dan pemukiman. Secara lebih terperinci, solusi yang ditawarkan untuk menyelesaikan permasalahan mitra adalah:

1. Meningkatkan pengetahuan dan pemahaman khalayak sasaran mengenai keanekaragaman buah lokal dan manfaatnya, serta pohonpohon penghasil buah lokal.

2. Meningkatkan keterampilan khalayak sasaran khalayak sasaran berkaitan penanaman dan pemeliharaan pohon-pohon penghasil buah lokal.

Berdasarkan hasil penelitian, metode pengajaran yang paling efektif dalam mengajarkan pendidikan lingkungan atau pendidikan konservasi pada anak-anak SD adalah berturut-turut metode pengalaman langsung, diikuti metode diskusi, selanjutnya metode demonstrasi atau metode percobaan (Monroe, Andrews, and Biedienweg, 2007; Muslicha, 2015). PKM ini akan mengaplikasikan metode pengalaman langsung dan metode diskusi.

\section{METODE PELAKSANAAN}

Keseluruhan kegiatan PKM ini diselesaikan dalam waktu 6 (enam) bulan. Lokasi kegiatan pengabdian adalah SD INPRES dan SD Katolik St. Agustinus Desa Warembungan Kecamatan Pineleng Kabupaten Minahasa Provinsi Sulawesi Utara. Pelaksanaan pengabdian dilakukan dalam beberapa kegiatan sebagai berikut.

1. Pengumpulan data berupa inventarisasi situasi lingkungan sekolah dan perilaku siswa berkaitan konservasi, diperoleh dengan cara survey lokasi dan wawancara terhadap mitra, lebih khusus lagi Kepala Sekolah dan guruguru masing-masing sekolah yang dimaksud.

2. Penyusunan program bersama mitra dan komunikasi program, sesuai permasalahan dan kebutuhan mitra.

3. Pembuataan modul pengajaran, serta persiapan alat dan bahan pendukung praktek (pengalaman langsung) siswa.

4. Pelaksanaan kegiatan pengajaran modul untuk mentransfer pengetahuan dan teknologi konservasi.

5) Pemantauan

6) Pelaporan dan publikasi.

Metode pengajaran yang digunakan dalam kegiatan pengabdian ini adalah perpaduan antara metode diskusi serta metode pengalaman langsung.

\section{HASIL DAN PEMBAHASAN}

Empat (4) tahapan pendidikan lingkungan yang dilaksanakan terhadap sasaran utama yaitu siswa-siswa SD mitra, dengan sasaran tambahan yaitu guru-guru SD mitra adalah sebagai berikut:

1. Menambah pengetahuan tentang keanekaragaman buah lokal dan manfaatnya.

2. Menumbuhkan apresiasi terhadap keanekaragaman buah lokal.

3. Menstimulasi motivasi untuk makan buahbuahan lokal dan menanam pohon-pohon penghasil buah lokal.

4. Melatih keterampilan menanam pohon dan menstimulasi tindakan secara mandiri.

Berdasarkan kesepakatan dengan kedua mitra, penyuluhan dilaksanakan pada tanggal 20 Agustus 2019 di masing-masing sekolah. Pemberian materi dilakukan dengan ditunjang tayangan power point yang mana slide-slidenya dirancang agar isinya padat tapi informatif dengan huruf yang mudah dibaca, dengan latar yang berwarna dan dilengkapi gambar bahkan suara agar menarik. Permainan tebak berhadiah, gerak 
EDUPRENEUR || Vol. 2, No 3, November 2019

Jurnal Pengabdian Kepada Masyarakat Bidang Kewirausahaan

dan lagu dilakukan di sela-sela pemberian materi sehingga siswa tertarik untuk mengikuti terus kegiatan penyuluhan sampai selesai. Setelah itu dilakukan penanaman di lingkungan sekolah dengan melibatkan siswa dan guru kedua sekolah tersebut. Untuk menyasar dampak yang lebih luas, dilakukan juga penyerahan bibit-bibit tanaman untuk ditanam di pekarangan, lingkungan pemukiman, dan kebun guru-guru kedua sekolah. Secara keseluruhan kegiatan disambut baik oleh kedua mitra dan berlangsung dengan lancar (Gambar 2-4).

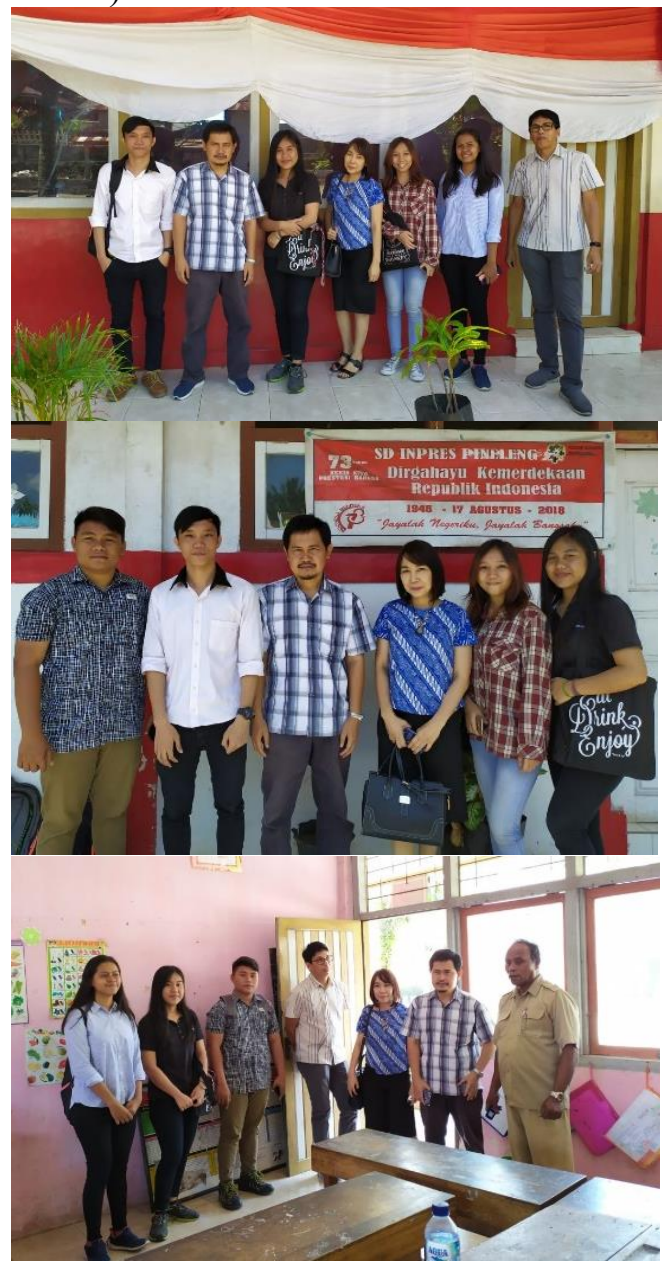

Gambar 2. Persiapan dengan Mitra

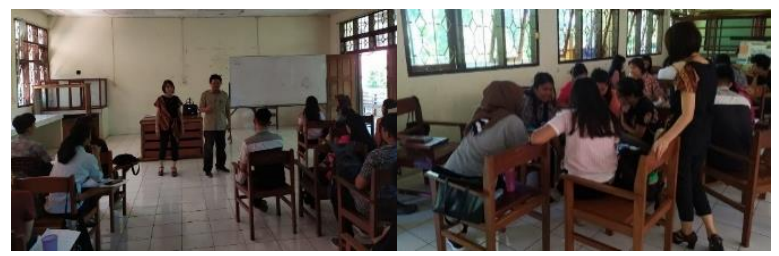

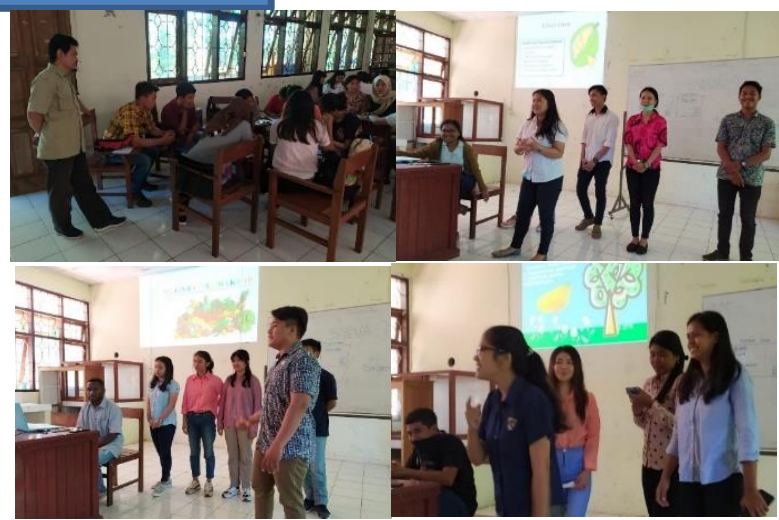

Gambar 3. Persiapan Internal Tim

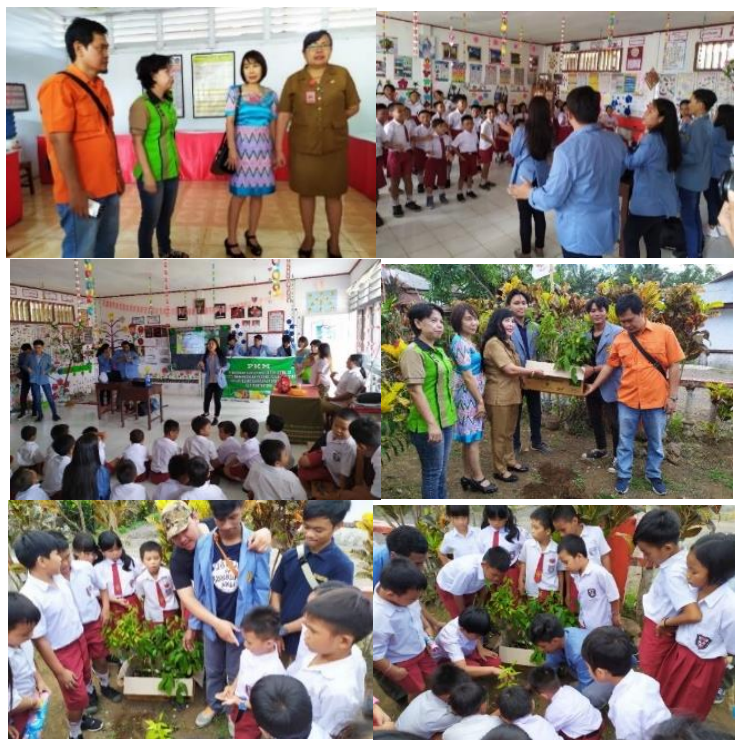

Gambar 4. Pelaksanaan

\section{KESIMPULAN}

Melalui pelaksanaan PKM lebih khusus lagi dalam acara tanya jawab dengan siswa dan diskusi dengan guru dan kepala sekolah, diperoleh gambaran adanya pemahaman bahwa konservasi keanekaragaman buah lokal memberikan manfaat secara langsung dan berkelanjutan, sekaligus mengkonfirmasi bahwa persepsi masyarakat mengenai dimensi produksi (ekonomi) dari biodiversitas flora dapat dibuktikan, sehingga mendorong pelestarian spesies sebagai prasyarat untuk mempertahankan keberlanjutan manfaatnya. Hal yang membedakan pengelolaan biodiversitas flora pada kawasan konservasi dengan pengelolaan pada lahan masyarakat adalah dalam hal inovasi dan eksplorasi. Pengelolaan biodiversitas flora melalui diversifikasi produk memungkinkan adanya eksplorasi dan inovasi berupa keseimbangan antara praktek konservasi dan upaya pemanfaatan. Hal ini berbeda dengan pengelolaan biodiversitas flora pada kawasan konservasi yang lebih mengedepankan fungsi konservasinya sebagai bank plasma nutfah, sedangkan unsur pengelolaan dan pemanfaatan belum optimal. 
EDUPRENEUR || Vol. 2, No 3, November 2019

Jurnal Pengabdian Kepada Masyarakat Bidang Kewirausahaan

Sementara, untuk anak-anak, dipikirkan perlu untuk memberikan pengalaman langsung mencicipi jenis-jenis buah lokal yang sudah sangat jarang ditanamkan dan atau dipasarkan.

\section{REFERENSI}

Adams, S. and Sayahl, S. 2017. Nature as Children's Space: A Systematical Review. The Journal of Environmental Education Vol. 48(5):291-321.

Ahmadi F., Sadeghi A. R., and Eskandarinezhad A. R. 2016. Ecological Quality Improvement of Urban Landscapes with Emphasis on Sustainable Development Principles Case Study: River of Darabad Valley, Tehran, Iran. European Journal of Sustainable Development 5(3): 91-102.

Asdak, C. 2014. Hidrologi dan Pengelolaan Daerah Aliran Sungai. Gadjah Mada Universty Press. Yogyakarta.

Bennett, E.M., Peterson, G.D. \& Gordon, L.J. 2009. Understanding relationships among multiple ecosystem services. Ecology Letters Vol. 12: 1394-1404.

Bryan, B.A., Raymond, C.M., Crossman, N.D. \& MacDonald, D.H. 2010. Targeting the management of ecosystem services based on social values: where, what, and how? Landscape and Urban Planning Vol. 97: 111-122.

de Groot, R.S., Alkemade, R., Braat, L., Hein, L. $\&$ Willemen, L. 2009. Challenges in integrating the concept of ecosystem services and values in landscape planning, management and decisionmaking. Ecological Complexity Vol. 7: 260-272.

Hacieminoglu, E. 2015. Elementary School Students' Attitude toward Science and Related Variables. International Journal of Environmental and Science Education Vol. 11(2):35-52.

Monroe, M. C., Andrews, E., and Biedienweg, K. 2007. A framework for Environmental Education Strategies. Applied Environmental Education and Communication 6: 205-216.
Muslicha, A. 2015. Metode Pengajaran dalam Pendidikan Lingkungan Hidup pada Siswa Sekolah Dasar (Studi pada Sekolah Adwiyata di DKI Jakarta). Jurnal PendidikanVol. 16(2): 110-126.

Neolaka, A. 2008. Kesadaran Lingkungan. PT Rinika Cipta. Jakarta.

Purwanto, A. 2012. Pengaruh Paket Pembelajaran Pendidikan Lingkungan Hidup Dan Gaya Kognitif Terhadap Kemampuan Memecahkan Masalah Lingkungan. Jurnal Pendidikan Lingkungan dan Pembangunan Berkelanjutan Vol. 13(1):55-68.

Reyers, B., O'Farrell, P.J., Cowling, R.M., Egoh, B.N., Maitre, D.C.L. and Vlok, J.H.J. 2009. Ecosystem services, land-cover change, and stakeholders: finding a sustainable foothold for a semiarid biodiversity hotspot. Ecology and Society Vol.14(38)

http://www.ecologyandsociety.org/vol14/ iss $1 / \operatorname{art} 38$.

Rombang, J., A. Thomas, F., Saroinsong. 2017. Pendidikan Konservasi tentang Pembuatan Lubang Resapan Biopori di SD GMIM 1 dan SDN 2 Tomohon. Abdimas Vpl 10(2): 44-52.

Saroinsong, F. B. dan J. I, Kalangi. 2016. Teknik Pengelolaan Sumber Daya Alam untuk Konservasi di Area Pemukiman. Jurnal Abdimas Vol 9 No 1.

Saroinsong, F. B. dan J. I, Kalangi. 2018. Diseminasi Pengelolaan RTH Pemukiman untuk meningkatkan Biodiversitas Flora. Edupreneur Vol 1 No 3: 54-61.

Saroinsong, F. B., W. Nurmawan, R. D. E. Sendouw. 2018. Pendidikan Konservasi untuk Siswa SD di Kelurahan Kleak Kota Manado tentang Pengendalian Banjir. Jurnal Dinamika Pengabdian Vol 10(11):16-21.

Sasaoka, M., Laumonier, Y. 2012. Suitability of Local Resource Management Practices Based on Supernatural Enforcement Mechanisms in the Local Social-cultural Context. Ecology and Society Vol. 17(4) 
EDUPRENEUR || Vol. 2, No 3, November 2019

Jurnal Pengabdian Kepada Masyarakat Bidang Kewirausahaan

http://www.ecologyandsociety.org/

vol17/iss $4 /$ art6/

Setyowati, D. L, Sunarko, R, Sedyawaati, S. M. R. 2014. Pendidikan Lingkungan Hidup. Universitas Negeri Semarang. Semarang.

Simbolon, B. R. 2010. Paket Materi Inkuiri dalam Pendidikan Lingkungan Hidup untuk Meningkatkan Perilaku Berwawasan Lingkungan Siswa SD di Jakarta. Jurnal Pendidikan Lingkungan dan Pembangunan Berkelanjutan Vol. 11(2): $1-20$.

Soendarti, M. 2017. The Effect of Learning Discovery Model on The Learning Outcomes of Natural Science of Junior High School Students Indonesia. International Journal of Environmental and Science Education Vol. 12(10):22132216.

Soerjani, M. 2009. Pendidikan Lingkungan, Sebagai Dasar Kearifan Sikap Bagi
Kelangsungan Kehidupan Menuju Pembangunan Berkelanjutan. Yayasan Institut Pendidikan dan Pengembangan Lingkungan. Jakarta.

Tugurian, L. P. \& Carrier, S. J. 2017. Children's environmental identity and the elementary science classroom. The Journal of Environmental Education Volume 48, 2017 - Issue 3 Pages 143-153.

Wascher, D. \& Haines-Young, R. 2009.

Assessing landscape functions with broad-scale environmental data: insights gained from a prototype development for Europe. Environmental Management Vol. 44: 1099-1120. 